\title{
Comparison of Electrocoagulation Process and Other Treatment Technologies in Fluoride Removal from Groundwater
}

\author{
${ }^{* 1}$ Benan Yazici Karabulut and ${ }^{2}$ Ayse Dilek Atasoy \\ ${ }^{* 1,2}$ Faculty of Engineering, Department of Environmental Engineering Harran University, Turkey
}

\begin{abstract}
Groundwater is one of the most important natural resources in the world and plays a very important role in the supply of drinking water. Fluoride is probably one of the most common groundwater pollutants in the world for various reasons (structure of soil and rocks, etc.). The concentration of fluoride in groundwater above $1.5 \mathrm{mg} / \mathrm{L}$ begins to pose some risks to human health. Various conventional techniques such as adsorption, ion exchange, reverse osmosis, nanofiltration, precipitation have been developed for the removal of fluoride from water. However, they have several limitations, such as posttreatment re-treatment, less efficiency and higher installation costs. The electrocoagulation process is an effective technology for fluoride removal within conventional techniques. In this study, fluoride removal technologies are emphasized, and the studies done in this field are examined. The aim of this study is to investigate the advantages of electrocoagulation method in fluoride removal and to compare electrocoagulation process with other treatment technologies.
\end{abstract}

Key words: Fluoride, groundwater, electrocoagulation, membrane processes.

\section{Introduction}

Water pollution is an important issue with various consequences for life on earth. It is mainly caused by industrial pollution and anthropogenic activities [1]. Fluoride in groundwater is a serious problem [2]. Groundwater is the most valuable fresh water used for drinking purposes in different areas. The discharge of some wastewater leads to fluoride contamination in surface and groundwater.

According to WHO standard, the optimum fluoride level in drinking water is between 0.5 and $1.0 \mathrm{mg} / \mathrm{L}[3,4]$. Fluoride contents higher than the permissible levels lead to negative effects on the human health. Therefore, it is considered a geogenic contaminant that causes dental fluorosis $(>1.5 \mathrm{mg} / \mathrm{L})$ and skeletal fluorosis (>4.0 mg/L) [5]. More than 200 million people in the world were directly affected from the fluoride. Endemic fluorosis originating from the consumption of high fluoride water was observed also in some parts of Anatolia. Volcanic formations are found in areas with high fluoride concentrations in ground waters.

The most widely used fluoride removal methods in the world are adsorption, coagulation/precipitation, electrodialysis, ion exchange, reverse osmosis and electrocoagulation [6-9]. Adsorption and coagulation/precipitation methods are conventional techniques but their removal efficiency lower than the others. Although high removal efficiencies are obtained by

*Corresponding author: Address: Faculty of Engineering, Department of Environmental Engineering Harran University, 63050, Sanliurfa TURKEY. E-mail address: benanyazici@ harran.edu.tr, Phone: +904143183000/1178 
methods such as nanofiltration and reverse osmosis high installation and operating costs are disadvantageous. In contrast, the electrocoagulation process is a green and clean also a low-cost method under suitable conditions.

In this study, a summary of published data on some important findings and a current literature source are presented and the results are discussed.

\section{Fluoride Removal Technologies from Groundwater}

There are many conventional methods for fluoride removal from groundwater. Some of these are discussed below.

\subsection{Precipitation/Coagulation Method}

The roots of the defluoridation processes is based on the early 1930s. Because researchers from all the world have been trying to improve a sustainable, clean and cost-effective technology to decrease $\mathrm{F}$ concentrations in groundwater. Chemical precipitation technique involves addition of aluminum salts along with lime to the F rich water followed by flocculation and sedimentation or filtration. The precipitation/coagulation method employs lime and alum salt to remove F-as precipitated $\mathrm{CaF}_{2}$. This step is followed by removing F-remaining in solution after coprecipitation and sorption onto the precipitated $\mathrm{Al}(\mathrm{OH})_{3}[10]$.

\subsection{Membrane Processes}

In recent years, membrane-based techniques have got a lot of attention due to their performance and reliability in operation for the removal of $\mathrm{F}$ from groundwater. At present, nanofiltration $(\mathrm{NF})$, reverse osmosis (RO), and electro-dialysis (ED) are the most popular membrane processes for F removal.

Nanofiltration (NF) and reverse osmosis (RO) were explored for fluoride and the other natural organic matter remediation of groundwater [11].

In $\mathrm{RO}$, pressure greater than the natural osmotic pressure is applied to the concentrated side of the membrane. Kettunen and Keskitalo (2000) evaluated the performance of a low energy RO membrane with a NF membrane [12]. Defluoridation of reverse osmosis-treated water is required thereby rendering this process more expensive in comparison to other techniques.

Nanofiltration (NF) is a relatively new process in contrast to other membrane processes; such as, RO, ultrafiltration (UF) and microfiltration (MF). It is emerging as a practically functional technology in treating industrial wastewaters. Defluoridation can be attained by changing the 
operating variables of the NF process; while simultaneously keeping the required $\mathrm{F}$ content in the water. Unfortunately, high pressure operation and high energy consumption is still a challenge for NF and RO membranes [13].

In electrodialysis, a direct current (DC) is used as a driving force to transport ions through ion exchange membranes. Electrodialysis process is used for the concentration of electrolyte solutions, and for the dilution or desalination of solutions [18,19]. One of the advantages of ED process is the capability to produce safe drinking water with low energy consumption [20,21]. In addition, ED process is a simple operation without applied pressure for ion removal like NF and RO processes $[14,15]$.

\subsection{Ion-Exchange Method}

Many reports have highlighted the efficacy of ion exchange with other techniques. Usually, ion Exchange technique removes $\mathrm{F}$ by adsorption rather than exchanging ions. The fundamental reason is that the fluoride concentration is comparably lower than other ions present in water. Cation exchange resins are more selective for $\mathrm{F}$ removal than anion exchange resins [16]. However, the defluoridation capacity and selectivity for $\mathrm{F}$ is dependent on the type of resin. The loading of metal ions influences the fluoride removal drastically, owing to variations in their properties [17]. Thus, it is difficult to maximize the defluoridation capacity (DC) of ion exchange resins while simultaneously enhancing the F selectivity.

Ion exchange offers very high operating costs but is very efficient [18]. However, one of the disadvantages is that when all low affinity ions on the resin are replaced with higher affinity ions, the resin is depleted and must be regenerated or replaced. Therefore, the regeneration process results in the formation of significant amounts of concentrated saline, which creates problems in the application of ion exchange systems. Regularly filling the brine tank and material cost make the system unfavorable $[19,20]$.

\subsection{Adsorption Method}

Adsorption process is generally one of the preferred methods in water treatment with ease of design. Therefore, it has a wide application area in water pollution control. Adsorption is regarded as an attractive method for aqueous fluoride removal. Adsorption is effective, convenient, easy to design and operate, and more importantly low cost [7]. Some methods are being developed to change the surface properties of adsorbents physically and chemically. Fluoride adsorption from water is controlled by $\mathrm{pH}$, temperature, sorption kinetics, sorbent 
particle size, sorbent/sorbate concentrations and adsorbent surface area [7]. However, the adsorption process is an old and conventional method. Adsorption is a function of adsorbent concentration and solution temperature. Adsorption is a surface process and the surface properties of adsorbent are very important. The majority of adsorption occurs when the mixture reaches equilibrium. The mass of the liquid or gas adsorbed per gram of solid depends on the specific surface area of the solid, the concentration of solute in equilibrium in solution, the temperature, the structure of the molecules present. It has been observed in recent studies that more effective and innovative methods are being replaced by this process.

\section{Removal of Fluoride by Electrocoagulation Process}

Electrocoagulation (EC) appears to be a promising physicochemical technology to remove various pollutants $[21,22]$ and is also effective in fluoride removal. It is a very successful and conventional method for removal of pollutants from groundwater. In the EC process, advantages such as environmental compatibility, energy efficiency, cost effectiveness, better automation, simple equipment requirements, low sludge production, and the ability to cope with various pollutants have made this method more attractive [23,24].

A simple EC process consists of electrode, reactor and power supply [25]. In the EC process, direct current (DC) is generally applied to generate the electric current through the electrodes [26]. Aluminum ( $\mathrm{Al})$ and iron (Fe) electrode types are more preferred in electrocoagulation.

EC involves in situ generation of coagulants by electrocoagulation of aluminum electrodes. Aluminum cations are generated the anode (1) and hydrogen gas is evolved at the cathode (2) [27].

Anode: $\quad \mathrm{Al}_{(\mathrm{s})} \rightarrow \mathrm{Al}_{(\mathrm{aq})}{ }^{3+}+3 \mathrm{e}^{-}$

Katode: $3 \mathrm{H}_{2} \mathrm{O}+3 \mathrm{e}^{-} \rightarrow 1.5 \mathrm{H}_{2(\mathrm{~g})}+3 \mathrm{OH}^{-}$

During the dissolution of $\mathrm{Al}$ at the anode various aqueous aluminum species are produced. The aluminum cations are transformed to polymeric species and form $\mathrm{Al}(\mathrm{OH})_{3}$ precipitate:

$$
\mathrm{Al}_{(\mathrm{aq})}{ }^{3+}+3 \mathrm{H}_{2} \mathrm{O} \rightarrow \mathrm{Al}(\mathrm{OH})_{3}+3 \mathrm{H}^{+}
$$

The fluoride removal by EC was carried out by means of a chemical substitution in which $\mathrm{F}^{-}$ replaced $\mathrm{OH}^{-}$group from $\mathrm{Al}(\mathrm{OH})_{3}$ flocs. 
The use of electrocoagulation (EC) as well as electrocoagulation/flotation (EF) process is on the rise. It can be effectively employed to treat oily wastewaters, dye and textile industry effluents and removal of organic matter, heavy metals and fluoride [28]. EC is advantageous since no impurities are introduced and useful contents existing in raw water can be retained during defluoridation.

Other contaminants such as oils, dyes, viruses, phosphate, arsenic and nitrate from water can also be successfully removed by this method. The use of this technology is quite inexpensive and can be further reduced if renewable energy sources are used [29].

\section{Conclusions}

The techniques that have lower costs are based on adsorption/ionic exchange techniques, although they exhibit low fluoride removal efficiencies. In contrast, the largest fluoride removals are obtained with techniques using activated carbon or zeolites, and especially for membrane-based methods such as electrodialysis, reverse osmosis, although they present the highest operation costs. Electrocoagulation method exhibits a high efficiency of fluoride removal in the case of a continuous flow reactor, easy operation at a relative cost, and the possibility of using a fully automated system.

Various conventional techniques have been developed for the removal of fluoride from water such as adsorption, ion exchange, reverse osmosis, electrochemical and chemical methods. However, they have several limitations, such as post-treatment re-treatment, less efficiency and higher installation costs. The electrocoagulation process is an effective technology for fluoride removal within conventional techniques.

\section{References}

[1] Tyagi S, Rawtani D, Khatri N, Tharmavaram M. Strategies for Nitrate removal from aqueous environment using nanotechnology: A Review, Journal of water process engineering. 2018;21:84-95.

[2] Crévecoeur S, Debacker V, Joaquim-Justo C, Gobert S, Scippo ML, Dejonghe W, Martin P, Thomé JP. Groundwater quality assessment of one former industrial site in Belgium using a TRIAD-like approach. Environ. Pollut, 2011;159:2461-2466. 
[3] Wang Y, Reardon EJ. Activation and regeneration of a soil sorbent for defluoridation of drinking water, Appl. Geochem. 2001;16:531-539.

[4] Ghorai S, Pantk K. Equilibrium, kinetics and breakthrough studies for adsorption of fluoride on activated alumina, Sep. Purif. Technol. 2005;42:265-271.

[5] Liu H, Gao Y, Sun L, Li M, Li B, Sun D. Assessment of relationship on excess fluoride intake from drinking water and carotid atherosclerosis development in adults in fluoride endemic areas, China, Int. J. Hyg. Environ. Health, 2014;217:413-420,

[6] Jacks G, Bhattacharya P, Chaudhary V, Singh KP. Controls on the genesis of some highfluoride groundwaters in India. Appl. Geochem. 2005;20:221-228.

[7] Loganathan P, Vigneswaran S, Kandasamy J, Naidu R. Defluoridation of drinking water using adsorption processes. J. Hazard. Mater. 2013;248-249:1-19.

[8] Tahaikt M, Habbani RE, Haddou AA, Achary I, Amor Z, Taky M, Alamib A, Boughriba A, Hafsi M, Elmidaoui A. Fluoride removal from groundwater by nanofiltration. Desalination, 2007;212:46-53.

[9] Behbahani M, Moghaddam MA, Arami M. Techno-economical evaluation of fluoride removal by electrocoagulation process: optimization through response surface methodology. Desalination, 2011;271:209-218.

[10] Liu R, Zhu L, Gong W, Lan H, Liu H, Qu J. Effects of fluoride on coagulation performance of aluminum chloride towards Kaolin suspension. Colloids Surf. Physicochem. Eng. Aspects, 2013;421:84-90.

[11] Shen J, Schäfer AI. Factors affecting fluoride and natural organic matter (NOM) removal from natural waters in Tanzania by nanofiltration/reverse osmosis. Sci. Total Environ. 2015;527-528:520-529.

[12] Kettunen R, Keskitalo P. Combination of membrane technology and limestone filtration to control drinking water quality. Desalination, 2000;131:271-283.

[13] Ben Nasr A, Charcosset C, Ben Amar R, Walha K. Defluoridation of water by nanofiltration, J. Fluor. Chem. 2013;150:92-97. 
[14] Cheng C, White N, Shi H, Robson M, Bruening ML. Cation separations in electrodialysis through membranes coated with polyelectrolyte multilayers, Polymer, 2014;55:1397-1403.

[15] Moon SH, Yun SH. Process integration of electrodialysis for a cleaner environment, Curr. Opin. Chem. Eng. 2014;4:25-31.

[16] Meenakshi S, Viswanathan N. Identification of selective ion-exchange resin for fluoride sorption. J. Colloid Interf. Sci. 2007;308:438-450.

[17] Luo F, Inoue K. The removal of fluoride ion by using metal (III)-loaded amberlite resins. Solvent Extr. Ion. Exch. 2004;22:305-322.

[18] Ansari MH, Parsa JB. Removal of nitrate from water by conducting polyaniline via electrically switching ion exchange method in a dual cell reactor: Optimizing and modeling, Separation and Purification Technology, 2016;169:158-170.

[19] Palko JW, Oyarzun DI, Ha B, Stadermann M, Santiago JG. Nitrate removal from water using electrostatic regeneration of functionalized adsorbent, Chemical Engineering Journal, 2018;334:1289-1296.

[20] Ruiz-Bevia F, Fernandez-Torres MJ. Effective catalytic removal of nitrates from drinking water: An unresolved problem?, Journal of Cleaner Production, 2019;217:398-408.

[21] Hakizimana JN, Gourich B, Chafi M, Stiriba Y, Vial C, Drogui P, Naja J. Electrocoagulation process in water treatment: a review of electrocoagulation modeling approaches, Desalination, 2017;404:1-21.

[22] Nariyan E, Sillanpää M, Wolkersdorfer C. Uranium removal from Pyhäsalmi/ Finland mine water by batch electrocoagulation and optimization with the response surface methodology, Separation and Purification Technology, 2018;193:386-397.

[23] Amooey AA, Ghasemi S, Mirsoleimani-azizi SM, Gholaminezhad Z, Chaichi MJ. Removal of Diazinon from aqueous solution by electrocoagulation process using aluminum electrodes, Korean Journal of Chemical Engineering, 2014;31:1016-1020.

[24] Lacasa E, Cañizares P, Sáez C, Martínez F, Rodrigo MA. Modelling and cost evaluation of electro-coagulation processes for the removal of anions from water, Separation and Purification Technology, 2013;107:219-227. 
[25] Kobya M, Delipinar S. Treatment of the baker's yeast wastewater by electrocoagulation, Journal of hazardous materials, 2008;154:1133-1140.

[26] Ghanizadeh G, Shariati neghab G, Salem M, Khalagi K. Taguchi experimental design for electrocoagulation process using alternating and direct current on fluoride removal from water, Desalination and Water Treatment, 2016;57:12675-12683.

[27] Zhu J, Zhao H, Ni J. Fluoride distribution in electrocoagulation defluoridation process, Seperation and Purification Technology, 2007;56:184-191.

[28] Hu CY, Lo SL, Kuan WH. Effects of the molar ratio of hydroxide and fluoride to Al(III) on fluoride removal by coagulation and electrocoagulation. J. Colloid Interf. Sci. 2005;283:472-476.

[29] Kalaruban M, Loganathan P, Kandasamy J, Naidu R, Vigneswaran S. Enhanced removal of nitrate in an integrated electrochemical-adsorption system, Separation and Purification Technology, 2017;189:260-266. 